\title{
JOB VERSUS HERCULES: VIRTUE IN THE ARTICLES OF THE BYZANTINE SUDA DICTIONARY OF THE $10^{\text {th }}$ CENTURY
}

\author{
Evgeny V. Stelnik \\ Volgograd State University, Volgograd, Russian Federation
}

\begin{abstract}
Introduction. In ancient mythology, the image of Hercules is one of the most popular, and his heroic cult is one of the most common. Having emerged from the "conglomerate of folk tales", the image of Hercules was actively assimilated by the Greek and then Roman literary tradition. Hercules was a very popular hero among Greek tragic and especially comic poets. In Roman times, the final systematization of the image took place. The key role in this process was played by the works of Apollodorus "The Mythological Library" ( $2^{\text {nd }}$ century BC), "Pictures" by Philostratus the Younger $\left(2^{\text {nd }}\right.$ century BC) and "Description of Hellas" by Pausanias ( $2^{\text {nd }}$ century BC). Within the framework of the classical tradition, the image of Hercules in Roman times was finally formed and unambiguous. Hercules is a hero, a demigod, the son of Zeus and Alcmene, who possessed amazing strength, who killed his children (and the children of his brother Iphicles) in an act of madness. He performed 12 labours at the request of Eurystheus. Hercules lived with the Lydian queen Omphale dressing in a woman's dress. He was poisoned by his wife Deianira, burned at the stake on Mount Eta and ascended to Olympus, where he became the spouse of Hebe. Methods. The hermeneutic methodology, which ensured the correct understanding and interpretation of the text of the Suda dictionary and the ancient texts, on which this "antique" dictionary was based, is used in the article. The toolkit of the hermeneutic circle (pre-understanding and understanding of the text, interpretation of the whole based on knowledge of its parts) made it possible to highlight key elements (plots, signs and symbols) of the philosophical image of Hercules in the entries of the dictionary. Results. We can see a kind of "muscular Christianity", when the strength of the body still corresponds to moral perfection and the withdrawal from the world does not contradict the active entry into the still polis institutions of urban life in Byzantine cities, among which the most important was the hippodrome and sports competitions. Christian authors actively used traditional sports metaphors and images of wrestling, but filled them with new Christian content. In the dictionary of the Suda, there is a kind of replacement of images that embody the samples of virtue. Hercules always loses to Job. It is indicative that the Christian rhetoric, relying on the philosophical symbolism of the apotheosis of Hercules, using the "sports" terminology of struggle, ignores the developed philosophical symbolism of Hercules, and fights against the mythological "fables" about Hercules. Using cynical and stoic terminology, Christian rhetoric opposes the comedic and dramatic image of Hercules, as Herodore of Heracles did in the $5^{\text {th }}$ century BC. That is, the enemy is borrowed from Christian rhetoric along with philosophical symbols and terminology describing a difficult life full of trials as a virtue.
\end{abstract}

Key words: virtue, philosophy, wrestling, athletes, Hercules, Job, Suda dictionary.

Citation. Stelnik E.V. Job Versus Hercules: Virtue in the Articles of the Byzantine Suda Dictionary of the $10^{\text {th }}$ Century. Vestnik Volgogradskogo gosudarstvennogo universiteta. Seriya 4. Istoriya. Regionovedenie. Mezhdunarodnye otnosheniya [Science Journal of Volgograd State University. History. Area Studies. International Relations], 2020, vol. 25, no. 6, pp. 253-258. (in Russian). DOI: https://doi.org/10.15688/jvolsu4.2020.6.20

ИОВ ПРОТИВ ГЕРАКЛА: ДОБРОДЕТЕЛЬ В СТАТЬЯХ ВИЗАНТИЙСКОГО СЛОВАРЯ СУДА Х ВЕКА

\section{Евгений Викторович Стельник}

Волгоградский государственный университет, г. Волгоград, Российская Федерация

Аннотация. В античной мифологии образ Геракла является одним из самых популярных, а его героический культ - одним из самых распространенных. Мифологический образ Геракла был активно освоен 


\section{ВИЗАНТИЙСКОЕ ПРАВОСЛАВИЕ}

древнегреческой, а затем и римской литературной традицией, особенно комедией. В философской традиции сформировался параллельный философский образ Геракла, который символически воплощает добродетели кинической и стоической философии. В византийском словаре Суда Х в., наполненном античными реминисценциями, Геракл рассматривается и в мифологическом и в философском контексте. Но киническая добродетель Геракла, для автора словаря, не выдерживает соревнования с христианской добродетелью, которую выражает ветхозаветный Иов. Иов побеждает Геракла как атлет атлета. Показательно, что мифологическое значение образа Геракла в христианской риторике вытесняется, а философский контекст встраивается в православную картину мира, но заменяется ветхозаветными образом Иова.

Ключевые слова: добродетель, философия, борьба, атлеты, Геракл, Иов, словарь Суда.

Цитирование. Стельник Е. В. Иов против Геракла: добродетель в статьях византийского словаря Суда Х века // Вестник Волгоградского государственного университета. Серия 4, История. Регионоведение. Международные отношения. -2020. - Т. 25, № 6. - C. 253-258. - DOI: https://doi.org/10.15688/jvolsu4.2020.6.20

Введение. В античной мифологии образ Геракла является одним из самых популярных, а его героический культ - одним из самых распространенных. Возникнув из «конгломерата народных сказаний» [3, с. 367], образ Геракла был активно освоен греческой, а затем и римской литературной традицией. О чудесном рождении Геракла повествует уже Илиада [13, XIX. 95]. Гераклу была посвящена поэма «Щит Геракла», написанная одним из авторов гесиодовского круга. Геракл описывался Паниасидом из Галикарнаса (VI в. до н. э.), Пиндаром (VI в. до н. э.), Гекатеем Милетским (VI-V вв. до н. э.), Аполлонием Родосским (III в. до н. э.). Писандр Родосский (VII-VI вв. до н. э.) собрал в единое повествование 12 легендарных подвигов. Так сложился стереотипный героический образ, известный каждому и в XXI в. Bo II в. Павсаний (IV.2,3) использовал термин «Гераклея», чтобы описать все эпические сказания о Геракле. А Аристотель в Поэтике (8 1451a) упоминает о нескольких эпических циклах (Гераклеях), описывающих всю жизнь Геракла.

Геракл был очень популярным героем у греческих трагических и особенно комических поэтов. Легендарный Креофил Самосский, современник Гомера, Писандр Камиренский (VII-VI вв.), Эпихарм (VI-V вв. до н. э.), Софрон (сер. V в. до н. э.), Софокл (V в.), Еврипид (V в. до н. э.), Архип (V в. до н. э.), Эсхил (V-IV вв. до н. э.), Аристофан (V-IV вв. до н. э.), Спинтарос (IV в. до н. э.) и Ринтон (IV в. до н. э.) активно использовали образ Геракла в своих поэмах.

В римское время произошла окончательная систематизация образа. Ключевую роль в этом процессе сыграли сочинения Аполлодора
«Мифологическая библиотека» (II в.), «Картины» Филострата младшего (ІІ в.) и «Описание Эллады» Павсания (II в.).

В рамках классической традиции образ Геракла в римское время являлся окончательно сложившимся и однозначным. Геракл - герой, полубог, сын Зевса и Алкмены, обладавший удивительной силой, в припадке безумия убивший своих детей (и детей своего брата Ификла). По требованию Эврисфея совершил 12 подвигов, жил у лидийской царицы Омфалы, одеваясь в женское платье, был отравлен своей женой Дейанирой, сгорел на костре на горе Эта и вознесся на Олимп, где стал супругом Гебы.

Методы. В статье использовалась герменевтическая методология, которая обеспечила корректное понимание и интерпретацию текста словаря Суда и античных текстов, на которые опирался этот «антикварный» словарь. Инструментарий герменевтического круга (предпонимание и понимание текста, истолкование целого на основании знания его частей) позволил выделить в статьях словаря ключевые элементы (сюжеты, знаки и символы) философского образа Геракла.

Анализ. Параллельно традиционному прочтению образа в драме и комедии в философских текстах образ Геракла приобрел неочевидное, символическое значение. В кинической, а потом стоической литературе Геракл стал символизировать непростую, но добродетельную жизнь.

Геракл прожил свою жизнь в борьбе, в трудах, в заботах и страданиях, но после смерти вознесся на небо и стал бессмертным (достиг апофеоза). Первоначально, видимо, не было речи о воздаянии, скорее всего, подразу- 
мевалось равновесие, когда тяжелая жизнь на земле уравновешивается апофеозом. Контраст между земной и небесными жизнями Геракла привлекал внимание многих древнегреческих авторов [12, p. 41].

Конечный успех (апофеоз) позволил авторам рассматривать тяжелую жизнь Геракла в новом контексте, когда мифологические действия и поступки очень неоднозначного персонажа получили расширительную трактовку. У Геродора Гераклейского, автора биографии Геракла в 17 книгах (400 г. до н. э.), Геракл представлен уже идеальным философом [4, c. 215], посвятившим свою жизнь моральному самосовершенствованию и служению науке [10, 31. F14].

Софисту Продику из Кеоса (V в. до н. э.) принадлежит сочинение «Геракл на распутье». Геракл в этом произведении представлен в виде юноши, который выбирает дорогу, по которой будет идти всю жизнь. Геракл выбирает между путем добродетели - чтобы идти по этой дороге надо иметь большую физическую силу - и путем наслаждений, который легок и приятен. Геракл выбирает тяжелый путь и стойко выдерживает удары судьбы как настоящий атлет.

У Антисфена (V-VI вв. до н. э.) Геракл, проведший всю жизнь в труде, становится примером добродетели [4, с. 215]; такое понимание образа стало универсальным для школы киников [2, с. 264]. Геракл борется с судьбой, и эта борьба стала универсальным примером. По словам Диогена Лаэртского, Антисфен всеми силами боролся с пороками. Для Антисфена примером в такой борьбе был именно Геракл, которому он посвятил свое сочинение «Геракл босоногий» ${ }^{1}$.

Атлетом называл себя стоик Посидоний (І в. до н. э.). Панкреатист - популярная стоическая метафора активной мужской энергии и философии вообще.

Показательно, что Геракл становился примером идеального правителя-философа. На пример мужества Геракла опирались в своем правлении Александр Македонский и римский император Коммод.

В византийском словаре X в. Суда (первое упоминание в 976 г.) [15, S. 261] образ Геракла представлен во всем его разнообразии. Автор словаря Суда нам неизвестен.
Bce, что мы можем о нем сказать, это то, что он интересовался военным делом, теологией и имел крайне плохие личные отношения с патриархом Полиевктом (956-970 гг.) - то есть почти ничего.

Словарь Суда - это колоссальный результат компиляции множества текстов. Это «Словарь» и «Мириобиблион» Фотия, «Этимологии», выдержки из трудов Константина VII, многочисленных схолий и предшествующих Суде словарей («Ономатологос» и «Эпитома») и многих других литературных трудов и сочинений. Словарь Суда, таким образом, - это результат аккумуляции целой культурной традиции.

Византийская культура настойчиво сохраняла традиционные античные образы [15, S. 13]. Старые античные образы сформировали христианскую риторику, и традиционный античный образ Геракла активно использовался в качестве риторического топоса $[14$, р. 36].

Византийский словарь Суда продолжает античную традицию символического прочтения образа Геракла.

Рассмотрим статьи словаря, посвященные Гераклу.

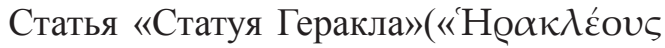
$\alpha \not \gamma \alpha \lambda \mu \alpha »$, eta 454). Словарь Суда рассказывает об одной константинопольской статуе Геракла, которая описывается также в сочинении Patria Constantinopoleos [18, p. 154-155]. Геракл в этой статье предстает перед нами не как мифический герой, а как «лучший из философов». В руке у этого Геракла три яблока, что, по словам автора словаря Суда, означает, что Геракл смог привести в гармонию состоящую из трех частей душу [19, eta 454]. Но эти же яблоки оказываются еще символами трех добродетелей: не гневаться, не стремится за выгодой и не тратить время попусту [19, eta 454]. Геракл приобрел эти яблоки-добродетели, когда убил своей дубиной дракона, то есть умерил свою страсть. А львиная шкура, которая укрывает Геракла, по мнению Суды, это не что иное, как «благородный ум, охвативший» Геракла.

Статья «Геракл» («Н $\alpha \kappa \lambda \tilde{\eta} \varsigma »$, eta 475) повторяет по смыслу статью eta 454 (Геракл - «лучший философ», львиная шкура, три яблока - три добродетели), но дополняет образ Геракла его дубиной, которая оказывается «аргументом его философии», которая 
завоевывает самых «смелых и здравомыслящих» [19, eta 475]. Приравнивание убеждения к насилию - распространенный топос древнегреческой риторики [1, с. 318], так что Геракл со своей «простой» дубиной и практической добродетелью противостоит изощренным и манерным философам и их абстрактным конструкциям. Философия Геракла - это прежде всего борьба со страстями, а не категориальное познание мира [16, p. 48]. Показательно, что Платон в словаре Суда тоже борец [19, pi 1707].

Ада Адлер, издатель словаря Суда, в своих комментариях проводила взаимосвязь между этой статьей и фрагментом из сочинения Иоанна Антиохийского [11, 4. 453], откуда автор Суды просто позаимствовал сюжет о Геракле-философе. Сам Иоанн Антиохийский опирался, видимо, на сочинение Геродора Гераклейского (V в. до н. э.).

В статье Иов («I $\omega \dot{\beta} »$, iota 471) уже ветхозаветный праведник описывается как «настоящий борец» ( $\dot{\alpha} \gamma \omega \nu\llcorner\sigma \tau \eta ́ \varsigma)$. Иов выходит

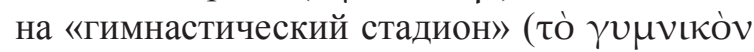

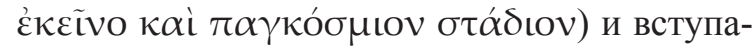
ет в борьбу с Сатаной, получая болезненные удары («вплоть до костей»). Иов стоит непреклонно как «голый атлет», «безоружный», «в одиночку». Иов стоит как «статуя», три раза бросает на землю своего противника и тем самым побеждает Сатану и в награду ( $\alpha \theta \lambda \omega \nu)$ за свою борьбу воскреснет вместе с Христом и будет жить вечно [17, р. 49]. Иов в добродетели превзошел апофеоз Геракла, когда воскрес вместе с Христом.

Христианская риторика активно опирается на философскую традицию, но идет дальше. Праведник Иов, претерпевший так же много лишений в своей жизни, оказывается для автора словаря более успешным, так как выиграл более значимый приз. Христианский атлет Иов победил языческого Геракла на его

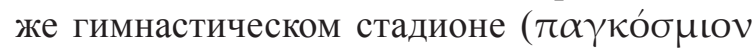

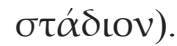

Х. Хунгер обращал внимание на то, как в рамках православной риторики старые греческие спортивные термины превращались в религиозные метафоры. Истоки этого процесса он находил в послании апостола Павла, а развитие - у Иоанна Злотоуста [14, р. 41].

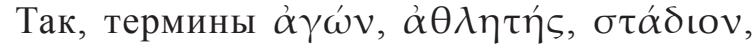

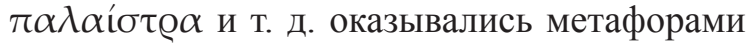
христианского усердия и борьбы / соревнования с Сатаной за спасение души. Не удивительно, что и Геракл как символ физической силы и покровитель спортивных упражнений превращался в персонажа, с которым соревнуется Иов и превосходит его.

Показательна трансформация терминов $\ddot{\alpha} \sigma \kappa \eta \sigma \iota \varsigma$ (упражнение) и $\dot{\alpha} \sigma \eta \tau \eta \dot{s ~(у п р а ж-~}$ няющийся в чем-либо гимнаст, атлет или борец), используемых словарем Суда в статье

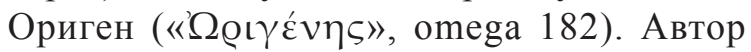
словаря цитирует «Церковную историю» Евсевия Памфила (около 265 г. - около 340 г.), у которого эти слова предстают в религиозном

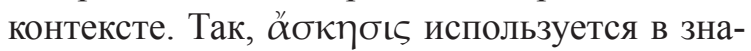
чении «тщательно изучать божественные истины», а аскет - это тот, кто усиленно изучает богословие [6, с. 225-226]. Постепенно в

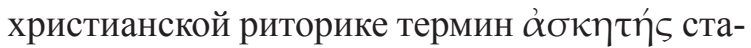
нет связываться с мученичеством [9, р. 143]. Похожую трансформацию пройдет и термин $\dot{\alpha} \theta \lambda \eta \tau \dot{\varsigma} \varsigma$ (атлет, борец) и приобретет значение «чемпион веры». То есть станет также синонимом мученичества.

Схожие спортивно-религиозные метафоры можно встретить в сочинениях Дионисия Ареопагита [5, 8.6], Марка Эфесского, Климента Александрийского [7, с. 85, 102, 284], Григория Назианзина, в комментариях Дидима Александрийского. По подсчетам К. Поляковой, у Иоанна Златоуста в текстах присутствуют сотни спортивных метафор [17, p. 51].

Спортивные образы присутствуют и в агиографии. Так, у Мосха есть описания соревнования на константинопольском ипподроме двух команд. «Партия» мужей в белых одеждах боролась с «партией» эфиопов. «Белая» команда, которая представляла ангелов, в конце концов, выиграла [8, с. 100].

Выводы. Перед нами - своеобразное «мускульное христианство» [17, р. 53], когда сила тела все еще соответствует моральному совершенству, а уход от мира не противоречит активному проникновению в еще полисные институты городской жизни византийских городов, среди которых важнейшее значение имел ипподром и спортивные состязания.

Христианские авторы активно использовали традиционные спортивные метафоры и образы борьбы, но наполняли их новым 
христианским содержанием. В словаре Суда происходит своеобразное замещение образов, воплощающих образцы добродетели. Геракл обязательно уступает Иову.

Показательно, что христианская риторика, опираясь на философскую символику апофеоза Геракла, используя «спортивную» терминологию борьбы, игнорирует разработанную философскую символику Геракла, но борется с мифологическими «баснями» о Геракле. Используя киническую и стоическую терминологию, христианская риторика противостоит комедийному и драматическому образу Геракла, как это делал Геродор Гераклейский еще в V в. до н. э. То есть противник позаимствован христианской риторикой вместе с философской символикой и терминологией, описывающей тяжелую, полную испытаний жизнь как добродетель.

\section{ПРИМЕЧАНИЕ}

${ }^{1}$ Показательно, что Геракл мог иметь прямо противоположное значение. У Паниасида из Галикарнаса он представляется похотливым обжорой и пьяницей; эта неумеренность была естественным отражением его неуемной силы. Эта традиция продолжается в комедиях Аристофана и Эпихарма.

\section{СПИСОК ЛИТЕРАТУРЫ}

1. Аверинцев, С. С. Поэтика ранневизантийской литературы / С. С. Аверинцев. - СПб. : Азбука-классика, 2004. - 480 с.

2. Алымова, Е. В., Караваева, С. В. Геракл как протагонист кинической литературы / Е. В. Алымова, С. В. Караваева // Вестник Русской христианской гуманитарной академии. - 2018. - Т. 19, вып. 4. C. 262-270.

3. Буркерт, В. Греческая религия. Архаика и Классика / В. Буркерт. - СПб. : Алетейя, 2004. $584 \mathrm{c}$.

4. Диоген Лаэртский. О жизни, учениях и изречениях знаменитых философов / пер. М. Л. Гаспарова. - М. : Мысль, 1998. - 576 с.

5. Дионисий Ареопагит. О божественных именах. О мистическом богословии / изд. подгот. Г. М. Прохоровым. - СПб. : Глагол, 1995. - 371 с.

6. Евсевий Памфил. Церковная история / коммент. и примеч. С. Л. Кравца. - М. : Изд-во Спасо-Преображенского Валаамского монастыря, 1993. $-448 \mathrm{c}$.

7. Климент Александрийский. Строматы. Т. 1 / подгот. текста, пер., пред. и коммент. Е. В. Афо- насина. - СПб. : Изд-во Олега Абышко, 2003. $544 \mathrm{c}$.

8. Рудаков, А. П. Очерки византийской культуры по данным греческой агиографии / А. П. Рудаков. - СПб. : Алетейя, 1997. - 296 с.

9. A Greek-English Lexicon of the New Testament and Other Early Christian Literature / ed. F. W. Danker. - Chicago : University of Chicago Press, 2000. -1108 p.

10. Die Fragmente der Griechischen Historiker. T. 1. Genealogie und Mythographie / ed. F. Jacoby. Leiden : Brill, 1995. - $313 \mathrm{~S}$.

11. Fragmenta Historicorum Graecorum. Vol. 4 / ed. K. Müller. - Parisiis : Firmin-Didot, 1885. - 856 S.

12. Holt, P. Herakles' Apotheosis in Lost Greek Literature and Art / P. Holt // L'antiquité classique. 1992. - T. 61. - P. 38-59.

13. Homeri Opera. Vol. 2 (Iliadis. XIII-XXIV) / ed. D. B. Monro, T. W. Allen. - Oxford : Clarendon Press, $1963 .-320 \mathrm{p}$.

14. Hunger, H. The Classical Tradition in Byzantine Literature: the Importance of Rhetoric / H. Hunger // Byzantium and the Classical Tradition: University of Birmingham, Thirteenth Spring Symposium of Byzantine Studies, 1979 / ed. M. Mullett, R. Scott. Birmingham : Centre for Byzantine Studies, University of Birmingham, 1981. - P. 35-47.

15. Krumbacher, K. Geschichte der byzantinischen Literatur von Justinian bis zum Ende des Oströemischen Reiches (527-1453) / K. Krumbacher. - München : C. H. Beck'sche Verlagsbuchhandlung (Oskar Beck), 1897. - $496 \mathrm{~S}$.

16. Moore, C. Heracles the Philosopher (Herodorus, Fr. 14) / C. Moore // The Classical Quarterly. - 2017. - Vol. 67, Issue 1. - P. 27-48.

17. Poliakoff, C. Jacob, Job, and Other Wrestlers: Reception of Greek Athletics by Jews and Christians in Antiquity / C. Poliakoff // Journal of Sport History. 1984. - Vol. 11, no. 2. - P. 48-65.

18. Scriptores originum Constantinopolitarum. Fasc. II / ed. T. Preger. - Leipzig : B.G. Teubner, 1907. $-276 \mathrm{p}$.

19. Suidae Lexicon. Vol. 2. (Lexicographi graeci, I) / ed. A. Adler. - Lipsiae : B.G. Teubneri, 1931. - 740 p.

\section{REFERENCES}

1. Averintsev S. S. Poetika rannevizantiyskoy literatury [Poetics of early Byzantine literature]. St. Petersburg, Azbuka-klassika Publ., 2004. 480 p.

2. Alymova E. V., Karavaeva S. V. Gerakl kak protagonist kinicheskoy literatury [Hercules as the protagonist of cynical literature]. Vestnik Russkoy khristianskoy gumanitarnoy akademii [Bulletin of the Russian Christian Humanitarian Academy], 2018, vol. 19, no. 4, pp. 262-270. 
3. Burkert V. Grecheskaya religiya. Arkhaika i Klassika [Greek religion. Archaic and Classical]. St. Petersburg, Aletheia Publ., 2004. 584 p.

4. Gasparov M.L., ed. Diogen Laertskiy. O zhizni, ucheniyakh i izrecheniyakh znamenitykh filosofov [Diogenes Laërtius. About the life, teachings and sayings of famous philosophers]. Moscow, Mysl Publ., 1998. 576 p.

5. Prokhorov G.M., ed. Dionisiy Areopagit. O bozhestvennykh imenakh. O misticheskom bogoslovii [Dionysius the Areopagite. About divine names. On mystical theology]. St. Petersburg, Glagol Publ., 1995. $371 \mathrm{p}$.

6. Kravts S.L., ed. Evseviy Pamfil. Tserkovnaya istoriya. [Eusebius of Caesarea. Church history]. Moscow, Izd-vo Spaso-Preobrazhenskogo Valaamskogo monastyrya Publ., 1993. 448 p.

7. Afonasina E.V., ed. Kliment Aleksandriyskiy. Stromaty [Clement of Alexandria. Stromata]. Vol. 1. St. Petersburg, Izd-vo Olega Abyshko Publ., 2003. $544 \mathrm{p}$.

8. Rudakov A.P. Ocherki vizantiyskoy kultury po dannym grecheskoy agiografii [Essays on Byzantine culture according to Greek hagiography]. St. Petersburg, Aletheia Publ., 1997. 296 p.

9. Danker F.W. A Greek-English Lexicon of the New Testament and Other Early Christian Literature. Chicago, University of Chicago Press, 2000. 1108 p.

10. Jacoby F., ed. Die Fragmente der Griechischen Historiker. T. 1. Genealogie und Mythographie. Leiden, Brill, 1995. 313 p.
11. Müller K., ed. Fragmenta Historicorum Graecorum. Vol. 4. Parisiis, Firmin-Didot, 1885. 856 p.

12. Holt P. Herakles' Apotheosis in Lost Greek Literature and Art. L'antiquité Classique, 1992, vol. 61, pp. 38-59.

13. Monro D.B., Allen T.W., eds. Homeri Opera. Vol. 2 (Iliadis. XIII-XXIV). Oxford, Clarendon Press, $1963.320 \mathrm{p}$.

14. Hunger H. The Classical Tradition in Byzantine Literature: the Importance of Rhetoric. Mullett M., Scott R., eds. Byzantium and the Classical Tradition: University of Birmingham, Thirteenth Spring Symposium of Byzantine Studies, 1979. Birmingham, Centre for Byzantine Studies, University of Birmingham, 1981, pp. 35-47.

15. Krumbacher K. Geschichte der byzantinischen Literatur von Justinian bis zum Ende des Oströemischen Reiches (527-1453). München, C.H. Beck'sche Verlagsbuchhandlung (Oskar Beck), 1897. 496 p.

16. Moore C. Heracles the Philosopher(Herodorus, Fr. 14). The Classical Quarterly, 2017, vol. 67, iss. 1, pp. 27-48.

17. Poliakoff C. Jacob, Job, and Other Wrestlers: Reception of Greek Athletics by Jews and Christians in Antiquity. Journal of Sport History, 1984, vol. 11, no. 2 , pp. 48-65.

18. Preger T., eds. Scriptores originum Constantinopolitarum. Fasc. II. Leipzig, B.G. Teubner, 1907. $276 \mathrm{p}$.

19. AdlerA., eds. Suidae Lexicon. Vol.2.(Lexicographi graeci, I). Lipsiae, B.G. Teubneri, 1931. 740 p.

\section{Information About the Author}

Evgeny V. Stelnik, Candidate of Sciences (History), Associate Professor, Department of Service and Tourism, Volgograd State University, Prosp. Universitetsky, 100, 400062 Volgograd, Russian Federation, analitika@volsu.ru, https://orcid.org/0000-0003-1097-1161

\section{Информация об авторе}

Евгений Викторович Стельник, кандидат исторических наук, доцент кафедры сервиса и туризма, Волгоградский государственный университет, просп. Университетский, 100, 400062 г. Волгоград, Российская Федерация, analitika@volsu.ru, https://orcid.org/0000-0003-1097-1161 